IP Periodica Polytechnica

Mechanical Engineering

61(4), pp. 261-265, 2017

https://doi.org/10.3311/PPme.10516

Creative Commons Attribution (i)

RESEARCH ARTICLE

\section{Admissibility of External Cracks in a Pipeline API X60 Using the SINTAP Procedure}

Kaddour Bahram ${ }^{1 *}$, Benattou Bouchouicha ${ }^{1}$, Mohamed Benguediab $^{1}$, Abdelkader Slimane ${ }^{1}$

Received 19 January 2017; accepted after revision 24 April 2017

\begin{abstract}
In this paper we tried to apply the failure assessment diagram method on an API X60 pipeline under two pressures 70 and 90 bar, this work will be divided into two parts; the first part will be devoted to modeling and simulation of a pipeline under pressure 70/90 bar. With abaqus software to determine the stress intensity factor of several ratios, The second part will focus on the exploitation of these results in order to draw the diagram of evaluation of the failure (FAD), once finished, We can pronounce on the vulnerability of the cracks which can cause the ruin of the pipeline to study, on mode of ruin and proposed safety factors.
\end{abstract}

\section{Keywords}

FAD, APIX60, crack, finite element, safety factor

\section{Introduction}

Breakdown is a problem that man will have to face as long as he builds buildings or builds structures. This problem is currently more crucial with the development of complex structures linked to technological progress. Advances in the knowledge of the mechanics of rupture now make it possible to better prevent the risk of rupture [1].

One of the most used and most answered methods in the field of diagnosis of cracks is the SINTAP because it offers several levels of studies [2, 3], in our case we have three information, yield strength, ultimate tensile strength and The critical intensity factor, we will in the following tried to apply this method on a pipeline API X60 under pressure 70 bar and 90 bar and to make a comparison between these two cases.

The choice of these two pressures is judicious; indeed the pressure of 70 bar is the working pressure, and the pressure of 90 bar the minimum test pressure at the factory. We will in some way tried to have if a few Cracks may not be detected during factory testing.

\section{Failure assessment diagram}

To determine whether a crack can cause structural failure, the FAD method uses two ratios: fragile fracture and plastic collapse. The brittle fracture ratio is computed from the crack front stress intensity, obtained by an elastic Abaqus analysis [4, 5]

- Brittle fracture:

$$
K_{r}=\frac{K_{I e}}{K_{C}^{*}}
$$

The plastic collapse ratio is calculated using the reference stress, which is calculated as a function of the size of the cracks.

- Plastic ruin:

$$
S_{r}=\frac{\sigma_{g}}{R_{c}}
$$

Where,

$$
\left\{\begin{array}{cl}
\sigma_{f}=\frac{\sigma_{y}+\sigma_{u}}{2} & \text { for } \sigma_{f}<1.2 \cdot \sigma_{y} \\
\sigma_{f}=1.2 \cdot \sigma_{y} & \text { for } \sigma_{f} \geq 1.2 \cdot \sigma_{y}
\end{array}\right.
$$


A dimensioning based on the rupture integrity diagram ensures. That the operating point $(\mathrm{Kr}, \mathrm{Sr})$ is found within the diagram delimited by the interpolation curve $\mathrm{Kr}=\mathrm{f}(\mathrm{Sr})$, the structure retains its integrity. If the calculated point is outside this area, the structure breaks down.

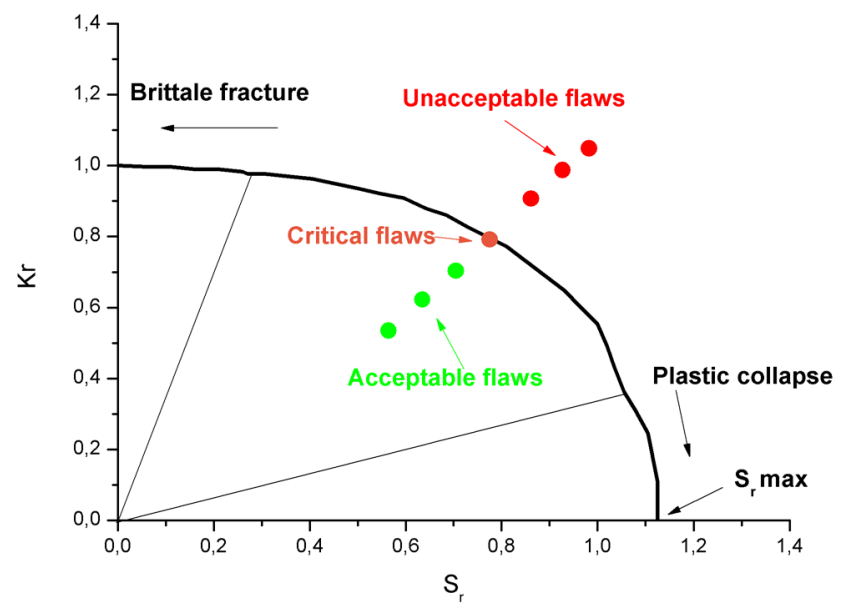

Fig. 1 Defaut failure Assessment diagram

$$
\begin{cases}\text { Brutale fracure } & 0 \leq S_{r} \leq 0.62 S_{r, y} \\ \text { Elasto-plastic fracture } & 0.62 S_{r, y} \leq S_{r} \leq 0.95 S_{r \max } \\ \text { plastic collapse } & 0.95 S_{r \max } \leq S_{r} \leq S_{r \max } \cdots \cdots\end{cases}
$$

Where is associated with the manufactured pressure.

\subsection{SINTAP equations}

The failure assessment line is defined by the following equations:

$f\left(S_{r}\right)=\left\{\begin{array}{lr}{\left[1+\frac{S_{r}{ }^{2}}{2}\right]^{-\frac{1}{2}}\left[0.3+0.7 \cdot \exp \left(-\mu \cdot S_{r}{ }^{6}\right]\right.} & \text { for } S_{r} \leq 1 \\ f(1) \cdot S_{r}{ }^{\frac{N-N}{2-N}} & \text { for } 1 \leq S_{r} \leq S_{r \max } \\ 0 & S_{r} \geq S_{r \max }\end{array}\right.$

With

$$
\begin{gathered}
\mu=\min \left[0.001 \cdot\left(\frac{E}{\sigma_{y}}\right) ; 0.6\right] \\
N=0.3 \cdot\left(1-\frac{\sigma_{y}}{\sigma_{u}}\right) \\
S_{r \max }=\frac{1}{2}\left(\frac{\sigma_{y}+\sigma_{u}}{\sigma_{y}}\right)
\end{gathered}
$$

For the evaluation of the failure assessment line only the tensile proprieties and young's modulus are required.

\section{$3 \mathrm{~J}$ Integral and stress intensity factor}

In order to evaluate the stress intensity factor. We tried to calculate it from the value of an integral independent of the integration contour proposed by Rice (Fig. 2). Is defined by the relation (I-12)

$$
\begin{gathered}
J=\int_{\Gamma}\left(W d y-\vec{T} \frac{d \vec{u}}{d x} d s\right) \\
W=W(x, y)=w(\varepsilon)=\int_{0}^{\varepsilon} \sigma_{i j} d \varepsilon_{i j}
\end{gathered}
$$

$\Gamma$ : Integration path surrounding the front of the crack

$\mathrm{W}$ : Deformation energy density, defined by relation 10

$\vec{T}$ : Traction vector, perpendicular to $\Gamma$, directed against the exterior of the integration path

$\vec{u}$ : Vector moving to position ds

ds: Arc element of integration path

$\varepsilon_{i j}$ : Deformation tensor

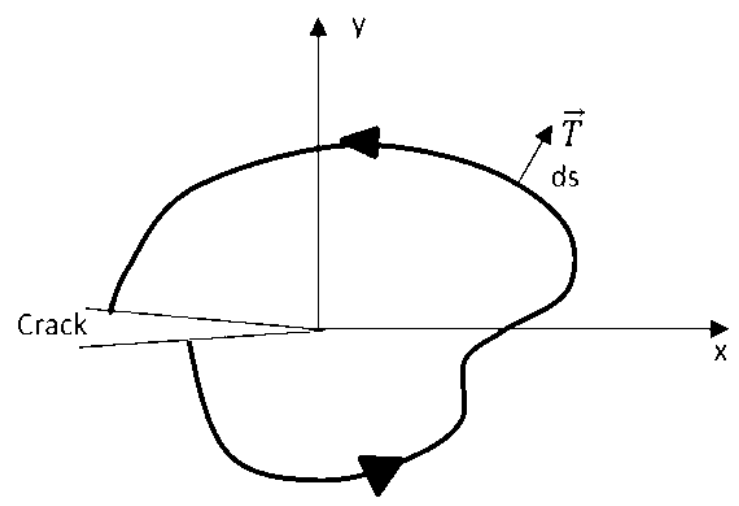

Fig. 2 Rice's J integral

The $\mathrm{J}$ integral is independent of the integration path chosen for a material having. An elastic nonlinear behavior, In the case of elastic linear behavior, the integral $\mathrm{J}$ is identical to $\mathrm{G}$, the energy released by stress relaxation. We have the following relation between $\mathrm{KI}$ and $\mathrm{J}$ :

$$
J=\frac{K_{I}^{2}}{E} \quad \text { Stress plane }
$$

$$
J=\frac{K_{I}^{2}}{E}\left(1-v^{2}\right) \quad \text { Deformation plane }
$$

\section{Modeling and boundary conditions}

For reasons of symmetry. A structured mesh in quadratic elements with 8 nodes is used and refinement to crack front to avoided the problem of singularity

\section{Pipeline study}

In the case studied, it is a pipeline API X60 with an outside diameter $\mathrm{D}=528 \mathrm{~mm}$ and a thickness $\mathrm{t}=7.1 \mathrm{~mm}$. 
Table 1 Mechanical Characteristics of API X60.

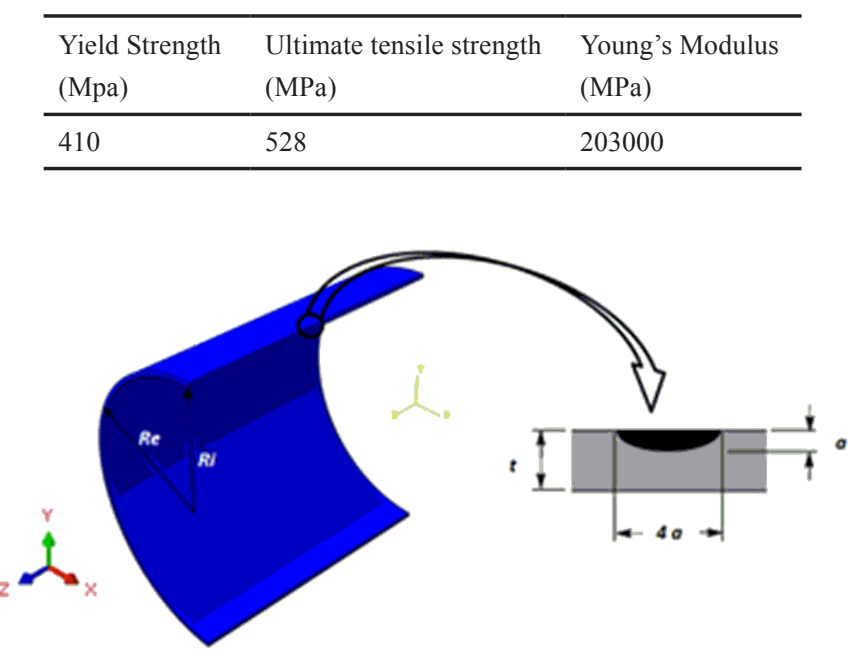

Fig. 3 Geometry and size of the crack

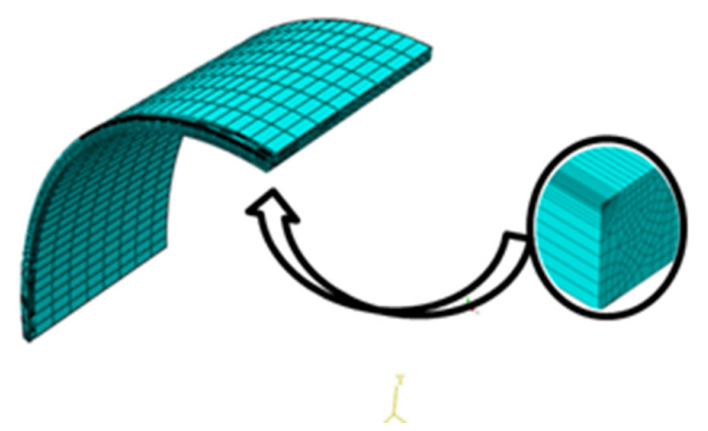

Fig. 4 Mesh of crack

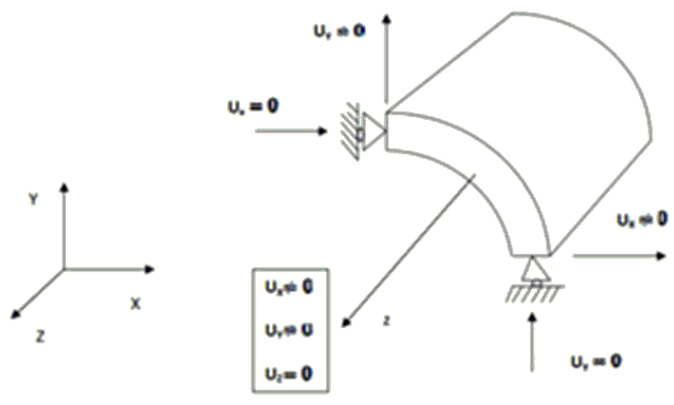

Fig. 5 Boundary conditions

\subsection{Stress intensity factor}

From the Fig. 6, noticing an increase in the stress intensity factor with the increase in pressure, this increase is increasing with the increase in the size of the crack.

This is logical because the reduction in the thickness of the tube caused by the increase of the crack greatly increases the stress in the crack front. It is also noted that for ratios $(a / t)$ $0.05,0.1,0.2,0.3$ and 0.4 for both pressures. It is found above the critical value of the stress intensity factor Factor $\mathrm{Sr}$ is calculated by Eq. (13)

$$
\sigma_{n}=\frac{P R_{\text {in }}}{(t-a)}
$$

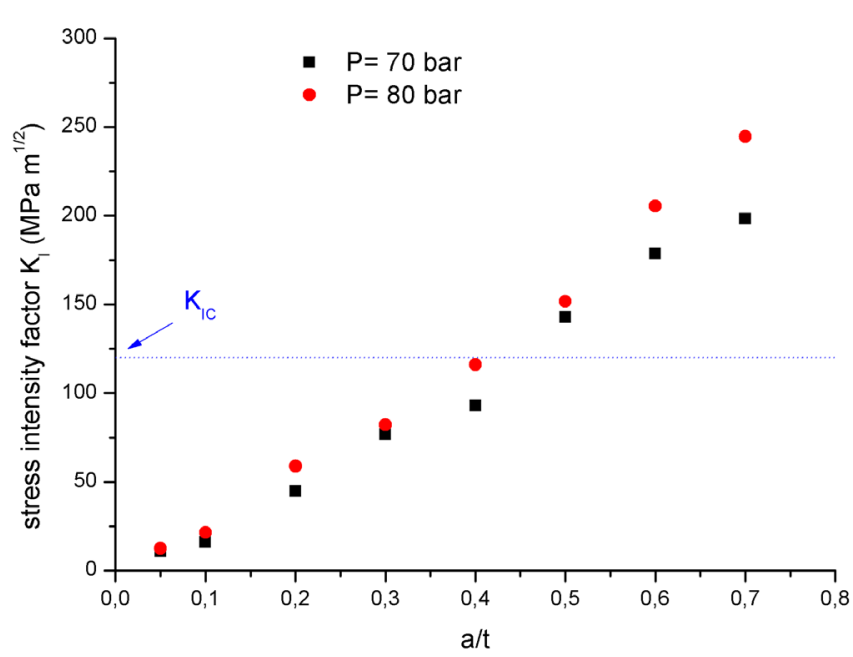

Fig. 6 Variation of Stress Intensity Factor with a/t Ratio for Different Pressures.

\subsection{FAD diagram}

From the calculus of the pair $(K r, S r)$ for ratios $a / t=$ $(0.05,0.1,0.2,0.3,0.4,0.5,0.6$ and 0.7$)$ the diagram is drawn in

Analyzing the preceding curve (Fig. 7) several remarks can be made:

- The ratios for the two pressures under the fault evaluation line are in the safety zone. On the other hand, the other ratios that are outside the fault evaluation line, they will cause the ruin our pipeline.

- The crack ratios 0.05 and 0.1 for both pressures belong to the area of plastic ruin by the other ratios 0.2 and 0.3 to 70 bar and the ratio 0.2 to 90 bar of pressure belongs to the elasto plastic fracture zone.

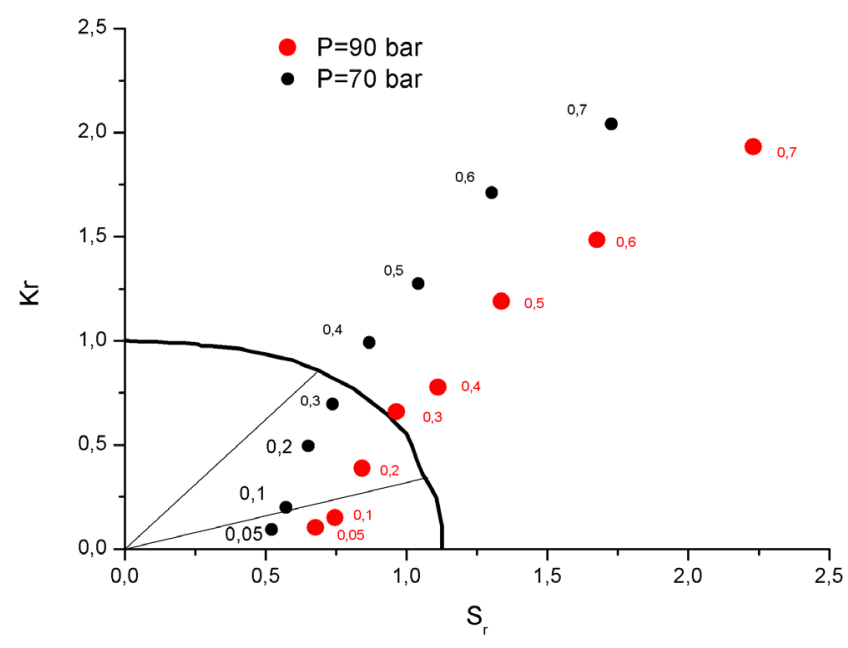

Fig. 7 FAD Diagram for Service Pressures of 70 bar and 90 bar.

Table 2 Critical crack for both pressures

\begin{tabular}{llll}
\hline $\begin{array}{l}\text { Pression } \\
(\text { bar })\end{array}$ & $\begin{array}{l}\mathrm{a}_{\mathrm{c}} \\
(\mathrm{mm})\end{array}$ & $\begin{array}{l}\mathrm{a} / \mathrm{t} \\
(\mathrm{mm})\end{array}$ & $\begin{array}{l}\mathrm{K}_{\mathrm{IC}} \text { API X60 } \\
(\mathrm{MPa} \sqrt{\mathrm{m}})\end{array}$ \\
\hline 70 & 2.435 & 0.34 & 120 \\
90 & 2.112 & 0.29 & 120 \\
\hline
\end{tabular}




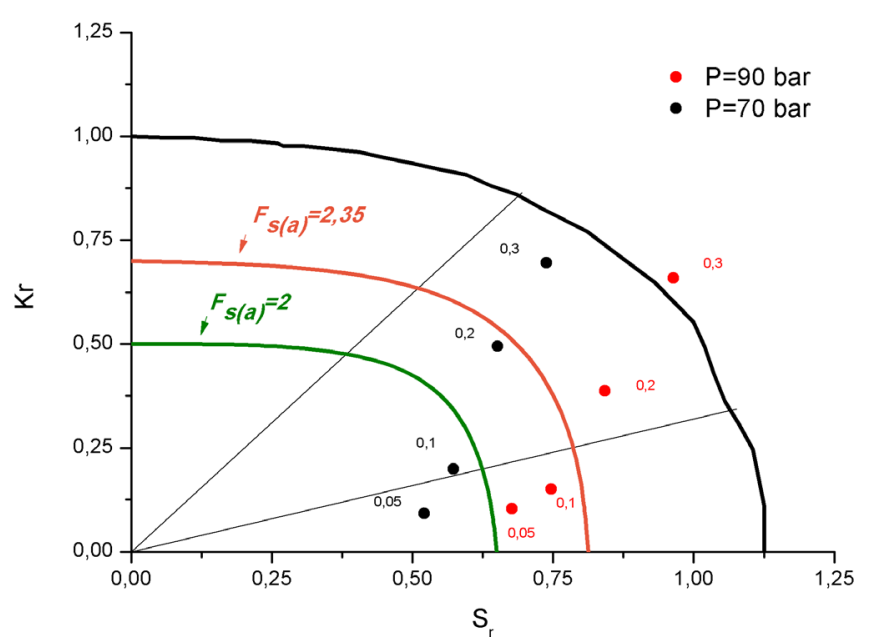

Fig. 8 FAD and safety factor

Taking a safety factor Fs (a) $=2$, it is noted that it covers that the ratios 0.05 and 0.1 at pressure 70 bar, given the almost linear arrangement of the ratios, one can predict the point of exit of the crack of the Zone of plastic ruin to the elasto-plastic rupture zone, and a safety factor Fs $(a)=2.37$ can be proposed by a simple calculation which covers all the ratios which is in the plastic ruin zone.

\section{Conclusion}

At the end of this modest work, we can conclude that:

- For API X52 pipelines, small cracks can be very dangerous and very vulnerable which can lead to a perfectly plastic ruin, In order to deal with this type of problem, it is recommended to take larger safety coefficients compared to the other ratios which are in the elasto-plastic fracture zone.

- This work also allowed us to calculate the critical crack for both pressures; it is $3.195 \mathrm{~mm}$ if the pressure is 70 bar and $2.868 \mathrm{~mm}$ for the pressure of 90 bar.

- For the regulatory tests carried out at the tube manufacturing plants, rations of the order of 0.1 and less can escape the tests because the minimum test pressure is 90 bar and this pressure is maintained for a few seconds, Contrary to the hydrostatic tests carried out before putting the pipelines under pressure (natural gas) which lasts 72 hours and the test pressure is 105 bar (1.5 x PMS).

- With this FAD digraph, decisions can be made concerning the repair or not of damage that may be subject to pipelines such as external scratches. Saving time and operating costs.

- This work also allowed us that small cracks may be in some cases more serious and more vulnerable.

- This work can be a platform for further work with higher levels of investigation.

\section{Nomenclature}

a Critical length of crack $\mathrm{mm}$

D outside diameter $\mathrm{mm}$

E Young's elastic modulus $\quad \mathrm{MPa}$

$J \quad$ Rice's J integral $\mathrm{kJ} / \mathrm{m}$

$K_{I} \quad$ Stress intensity factor $\quad \mathrm{MPa}{ }_{\mathrm{m}}$

$K_{I C} \quad$ Material toughness $\quad \mathrm{MPa} \bigvee_{\mathrm{m}}$

$P \quad$ Service pressure $\quad \mathrm{Pa}$

PMS Maximum operating pressure $\quad \mathrm{Pa}$

Rin Internal radius of pipe $\mathrm{mm}$

$t \quad$ Pipe wall thickness $\mathrm{mm}$

$\mu \quad$ Shear modulus $\quad \mathrm{GPa}$

$v \quad$ Poisson's ratio

$\sigma_{f} \quad$ Average flow stress $\quad \mathrm{MPa}$

$\sigma_{n} \quad$ Stress in the ligament ahead of the crack $\mathrm{MPa}$

$\sigma_{u} \quad$ Ultimate tensile strength $\mathrm{MPa}$

$\sigma_{y} \quad$ Yield strength $\quad \mathrm{MPa}$

\section{Acknowledgment}

I want to thank all the authors for their insightful comments and suggestions.

\section{References}

[1] Zhou, Y., Zhang, Z., Zhong, Q. "Improved reliability analysis method based on the failure assessment diagram." Chinese Journal of Mechanical Engineering. 25(4), pp. 832-837. 2012.

https://doi.org/10.3901/CJME.2012.04.832

[2] Han, J.-J., Ryu, H-W., Kim, Y-J., Kim, J-S., Oh, Y-J., Park, H-B. "Failure assessment diagram analysis of high density polyethylene pipes." Journal of Mechanical Science and Technology. 28(12), pp. 4929-4938. 2014. https://doi.org/10.1007/s12206-014-1113-3

[3] Pluvinage, G. "General approaches of pipeline defect assessment." In: Pluvinage, G., Hamdy Elwany, M. (eds.) Safety, Reliability and Risks associated with water, oil and Gas pipelines. NATO Science for Peace and Security Series. (pp. 1-22), Springer, Dordrecht, 2008.

https://doi.org/10.1007/978-1-4020-6526-2_1

[4] Pluvinage, G. "Pipe-defect assessment based on the limit analysis, failure-assessment diagram, and subcritical crack growth." Materials Science. 42(1), pp. 127-139. 2006.

https://doi.org/10.1007/s11003-006-0065-x

[5] Matvienko, Y. "Safety factors in structural integrity assessment of components with defects." International Journal of Structural Integrity. 4(4), pp. 457-476. 2013.

https://doi.org/10.1108/IJSI-09-2012-0022

[6] Pisarski, H. G., Wallin, K. "The SINTAP fracture toughness estimation procedure." Engineering Fracture Mechanics. 67(6), pp. 613-624. 2000. https://doi.org/10.1016/S0013-7944(00)00076-X

[7] Webster, S., Bannister, A. "Structural integrity assessment procedure for Europe-of the SINTAP programme overview." Engineering Fracture Mechanics. 67(6), pp. 481-514. 2000.

https://doi.org/10.1016/S0013-7944(00)00070-9

[8] Wiesner, C., Maddox, S. J., Xu, W., Webster, G. A., Burdekin, F. M., Andrews, R. M., Harrison, J. D. "Engineering critical analyses to BS 7910 - the UK guide on methods for assessing the acceptability of flaws in metallic structures." International Journal of Pressure Vessels and Piping. 77(14-15), pp. 883-893. 2000.

https://doi.org/10.1016/S0308-0161(01)00011-4 
[9] Zerbst, U., Hamann, R., Wohlschlegel, A. "Application of the European flaw assessment procedure SINTAP to pipes." International Journal of Pressure Vessels and Piping. 77(11), pp. 697-702. 2000. https://doi.org/10.1016/S0308-0161(00)00059-4

[10] Kwak, S. L., Joong Seong, L., Young Jim, K., Won, Y. "A probabilistic integrity assessment of flaw in zirconium alloy pressure tube considering delayed hydride cracking." International Journal of Modern Physics B. 17(8-9), pp. 1587-1593. 2003.

https://doi.org/10.1142/S0217979203019368

[11] Adib-Ramezani, H., Jeong, J., Pluvinage, G. "Structural integrity evaluation of X52 gas pipes subjected to external corrosion defects using the SINTAP procedure." International Journal of Pressure Vessels and Piping. 83(6), pp. 420-432. 2006. https://doi.org/10.1016/j.ijpvp.2006.02.023

[12] Cravero, S., Ruggieri, C. "Structural integrity analysis of axially cracked pipelines using conventional and constraint-modified failure assessment diagrams." International Journal of Pressure Vessels and Piping. 83(8), pp. 607-617. 2006. https://doi.org/10.1016/j.ijpvp.2006.04.004

[13] Wang, X., Tan, C-L. "T-stress solutions for cracks in rectangular plates with multiple holes." Structural Engineering and Mechanics. 26(5), pp. 557-568. 2007.

[14] Kanto, Y., Onizawa, K., Machida, H., Isobe, Y., Yoshimura, S. "Recent Japanese research activities on probabilistic fracture mechanics for pressure vessel and piping of nuclear power plant." International Journal of Pressure Vessels and Piping. 87(1), pp. 11-16. 2010. https://doi.org/10.1016/j.ijpvp.2009.11.010
[15] Bach, M., Wang, X. "Constraint-based fracture mechanics analysis of cylinders with internal circumferential cracks." Structural Engineering and Mechanics. 47(1), pp. 131-147. 2013.

https://doi.org/10.12989/sem.2013.47.1.131

[16] Wang, Z.-X., Zhang, R-F., Chao, Y. J., Lam, P-S. "Effect of mechanical property mismatch on failure assessment curve for welded joint with a semi-elliptical crack." International Journal of Applied Mechanics. 5(3), 2013.

https://doi.org/10.1142/S1758825113500294

[17] Kharrat, M., Ichchou, M. N. "Pipeline inspection using a torsional guidedwaves inspection system. Part 2: Defect sizing by the wave finite element method." International Journal of Applied Mechanics. 6(4), 2014. https://doi.org/10.1142/S1758825114500355

[18] Kharrat, M., Ichchou, M. N., Bareille, O., Zhou, W. "Pipeline inspection using a torsional guided-waves inspection system. Part 1: Defect identification." International Journal of Applied Mechanics. 6(4), 2014. https://doi.org/10.1142/S1758825114500343

[19] Farahpour, P., Babaghasabha, V., Khadem, M. "Stress intensity factor calculation for semi-elliptical cracks on functionally graded material coated cylinders." Structural Engineering and Mechanics. 55(6), pp. 1087-1097. 2015. https://doi.org/10.12989/sem.2015.55.6.1087

[20] Huang, W., Sridhar, N. "Fatigue Failure Risk Assessment for a Maintained Stiffener-Frame Welded Structure with Multiple Site Cracks." International Journal of Applied Mechanics. 8(2), 2016. https://doi.org/10.1142/S17588251165002[41 